\title{
Does melanin-based plumage coloration reflect health status of free-living birds in urban environments?
}

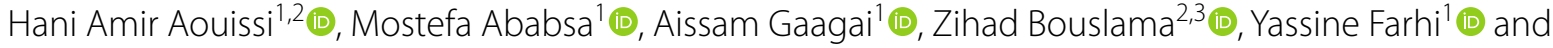 \\ Haroun Chenchouni ${ }^{4,5^{*}}$ (B)
}

\begin{abstract}
Background: Ecological functions and processes in urban ecosystems are governed by various human activities. City-adapted and city-exploiting animal species are expected to present certain specific behavioral and physiological traits in comparison to city-avoiders or conspecific individual frequenting less urbanized or rural environments. A trait of high importance, the plumage color polymorphism has been selected as the main study model and was correlated with different morphological and physiological parameters to highlight its importance in determining the possible health status of urban Feral Pigeons (Columba livia) in North African urban habitats.
\end{abstract}

Methods: Different body morphometrics, hematological and hemoparasitic parameters were quantified on freeliving Feral Pigeons in urban environments of northern Algeria. Moreover, plumage melanin-based coloration (MBC) was measured and the data collected at the individual scale was correlated with the previous parameters using linear and non-linear modeling approaches.

Results: Plumage MBC scores of the sampled Feral Pigeons ranged between $0.3 \%$ and $74.8 \%$. Among the 12 morphological traits measured, body weight, tail length and total length were deemed to be positively correlated with MBC. Darker morphs appeared to have more hemoparasites compared to lighter pigeons. Quite the same observation goes with the immunity but with non-linear trends. The number of monocytes and granulocytes increased with the increase in $\mathrm{MBC}$ levels in lighter morphs, while pigeons with high $\mathrm{MBC}$ scores exhibited negative relationships between MBC levels and the number of white blood cells.

Conclusions: Despite the existence of a number of studies demonstrating phenotypic directional selection, further studies are undoubtedly necessary to understand in detail the underlying mechanisms in species life-history strategies between differently colored individuals. Findings of this correlative study open exciting perspectives revealing that MBC can be considered a good indicator of and health status and adaptation strategies to changes in urban environments.

Keywords: Columba livia, Feather color polymorphism, Feral birds, Hematological indicators, Hemoparasitism, Immune ecophysiology, Urbanization, Urban ornithology

\footnotetext{
*Correspondence: chenchouni@gmail.com

${ }^{4}$ Department of Nature and Life Sciences, Faculty of Exact Sciences and Nature and Life Sciences, University of Larbi Tebessi, 12002 Tebessa, Algeria

Full list of author information is available at the end of the article
}

\section{Background}

The current trend of urban environments is increasing worldwide since the generalized urban sprawl in the twentieth century. Urbanization expansion caused the replacement of rural habitats by urban, industrial and original author(s) and the source, provide a link to the Creative Commons licence, and indicate if changes were made. The images or other third party material in this article are included in the article's Creative Commons licence, unless indicated otherwise in a credit line to the material. If material is not included in the article's Creative Commons licence and your intended use is not permitted by statutory regulation or exceeds the permitted use, you will need to obtain permission directly from the copyright holder. To view a copy of this licence, visit http://creativecommons.org/licenses/by/4.0/. The Creative Commons Public Domain Dedication waiver (http://creativeco mmons.org/publicdomain/zero/1.0/) applies to the data made available in this article, unless otherwise stated in a credit line to the data. 
other manmade sites ecosystems (Berry 1990). As artificial ecosystems, urban environments are mainly dependent on human activities and inputs (Grimm et al. 2000; Shochat et al. 2006). Major anthropogenic disturbances undoubtedly prevail, like light, noise, solid wastes and chemical pollutions (Pickett et al. 2011; Gaagai et al. 2017; Ouali et al. 2018). In general, there are two kinds of species in urban environments: specialists and generalists. Specialists can live only in a narrow range of conditions (diet, food, climate etc.), while generalists are able to survive a wide variety of conditions and changes in the environment. Native specialist species are becoming less abundant in urban (or disturbed) landscapes due to species turnover with replacement of specialists by cityadapted and city-exploiting species (Schultz et al. 2005; Le Viol et al. 2012). Under the global increase of urbanization, many populations are under the pressure to either alter and/or shift their natural ranges or adapt to new environments (Parmesan and Yohe 2003). Consequently, phenotypic differentiations arise in individuals close to the center of the range, a phenomenon called genetic paradox (Pérez et al. 2006). Since most range-edge populations have low genetic diversity, high phenotypic variation at the range-edge is likely partially underlain by phenotypic plasticity, i.e. the ability of one genotype to produce more than one phenotype when exposed to different environments (Kilvitis et al. 2017). For example, Hanson et al. (2020) claimed that epigenetic potential may play a role in House Sparrow (Passer domesticus) range expansions, even though it remains very difficult to understand how epigenetic potential affects the gene's expression, which is identical to the phenotypic plasticity at the individual, population, and species levels.

There is some evidence that the land use changes (Devictor et al. 2008a, b) and the climate (Davey et al. 2013) are driving decline of specialization in wild animal communities, leading to a functional biotic homogenization (Clavel et al. 2011). Urban-adapted and urban-exploiter species, in contrast to urban-avoider species, extensively benefit from various resources that urban environments provide such as the additional and the permanent foraging and nesting opportunities (Chenchouni 2017a; Chedad et al. 2021), which affects species population dynamics and distribution. In the same vein, populations of the Feral Pigeon (Columba livia) are expected to increase because of the wide ecological niche and large tolerance range of the species (Devictor et al. 2007). Then, its adaptive ability to urban environments and exploitation of different resources provided by humans makes it an excellent generalist synanthropic species (Marzluff 2001; Kark et al. 2007).

Bird species richness is highly variable following urbanto-rural gradient (Germaine et al. 1998; Blair 2004; Pal et al. 2019). The characteristics of rural individuals are different compared to their urban conspecifics, both at species and population levels (Luniak 2004; Møller 2009; Chenchouni 2017b). For example, urban populations usually have lower anti-predatory defenses (Blair 2004; Møller 2009), but have higher immune capacity (Fokidis et al. 2008; French et al. 2008), compared to rural populations of the same species (Evans et al. 2009). The term "urbanization syndrome", adopted by Luniak (2004), is defined as individuals colonizing the urban environment have particular characteristics compared to their conspecifics living in rural areas, and show sets of traits associated with the ability to colonize and thrive in the urban environment. It has also been demonstrated that the individuals living in urban areas live in a higher density population and are more tolerant to human presence compared to rural individuals (Møller 2009, 2010). Then the term "local adaptations to urban areas" was used by Evans et al. (2009) and defined it as the fact that directional selection in urban environments may explain such phenotypic divergence on several morphological, physiological and behavioral traits between rural and urban individuals. Studies concerning the evolutionary processes governing the phenotypic divergence observed between rural and urban avian (or animal in general) populations are still insufficient (Shochat et al. 2006; Evans et al. 2009; Ducatez et al. 2017).

Melanin-based coloration is mainly due to two pigments: pheomelanin, which is responsible for brown and reddish coloration, and eumelanin, which is responsible for black and grey coloration (Côte et al. 2018). These melanin pigments have a direct role on some biological functions, such as thermoregulation, camouflage and UV protection (Hill and McGraw 2006). Therefore, climate and predation play an important role in the evolution of melanin-based coloration (MBC) polymorphism (Vignieri et al. 2010). Regarding its strong genetic basis, $\mathrm{MBC}$ is an ideal choice to investigate urbanization syndrome (Roulin 2004). Besides, several studies stressed that there are significant differences in animal $\mathrm{MBC}$ between rural and urban areas (Obukhova 2001; Yeh 2004). For instance, darker individuals have often-higher reproductive success (Roulin et al. 2008; Jacquin et al. 2012), lower response to stress (Almasi et al. 2010; Corbel et al. 2016) and finally higher aggressiveness (Reyer et al. 1998; Quesada and Senar 2007) when compared with paler conspecifics. Briefly, differently colored individuals have demonstrated differences in reproduction (Krüger and Lindström 2001), energy homeostasis (Dreiss et al. 2010) and parasite resistance (Roulin et al. 2001; Chatelain et al. 2017). Furthermore, color polymorphism might reflect an adaptation to the urban environment (Johnston and Janiga 1995; Jacquin 2011; Chatelain et al. 
2014). Differences in bird species survival and/or dispersal are related to differences in individual and population MBC (Roulin and Altwegg 2007; Roulin et al. 2010; Van den Brink et al. 2012; Saino et al. 2013). However, some recent studies do not denote the same direction. For example, the lack of relationship between breeding performance, morph, and urbanization for the polymorphic African raptor might be related to prey abundance (Sumasgutner et al. 2018). In addition, the analysis of polymorphism in Black Sparrowhawk (Accipiter melanoleucus) has demonstrated that dark morphs have lower infections by haemosporidian parasites Haemoproteus nisi compared to paler ones, suggesting a higher parasitic resistance (McCarren et al. 2021). More recently, no relationship was found between eumelanism and the infection intensity in a large sample $(N=195)$ of Feral Pigeons (Nebel et al. 2020). These results were in line with the study of Jacquin et al. (2011) who attested that darker individuals are assumed to show stronger immune response, but blood parasite intensity was independent of melanism. In all cases, the discussion remains open, all the hypotheses must be taken into account, and each study could be of considerable importance.

Ornithological studies investigating urban environments in North Africa, especially in Algeria, are scarce. Information is still incomplete, fragmentary and lacking or even non-existent for some urban-adapted and urbanexploiter species. Excluding some studies (e.g. Bendjoudi et al. 2013, 2015), the most noteworthy urban studies have considered for example the phenotype of the Collared Dove (Streptopelia decaocto) (Belabed et al. 2013) and the impact of urban greenspaces on bird species richness and abundance (Aouissi et al. 2017). This study was intended as well to achieve an expanded knowledge about North African urban ornithology by providing various new data, specifically on the Feral Pigeon. This species originated from some domesticated forms of the wild Rock Pigeon and then it became inescapably one of the most common urban-exploiter species that successfully colonized most cities worldwide (Aouissi et al. 2015; Aouissi 2016).

Considering the controversial association between melanin-based polymorphism and immune function, we investigate the infection intensity of haemosporidian parasites (Plasmodium spp.) in relation to color morph of Feral Pigeons in the city of Annaba (northeastern Algeria). It is then noteworthy to mention two facts that have a crucial role in the prediction process acceleration. The first is the physiological interactions that involve immunity and parasites. These can be, in fact, complicated and dependent on a variety of factors. The second is the MBC-parasitism relationship, which has been understudied for a long time. Both of the previous issues do not pave for a convenient prediction of the response of wild populations to changing environments and disease risks (Martin 2009). Here, we consider it necessary to scrutinize the evidence that variation in melanin-based coloration has implications for parasitism. Primarily to making any hypotheses, it would be interesting to determine with analysis how our individuals' health could be studied. In this sense, multiple definitions raise for the terms "health" or "health status". For instance, it can be defined as a range of manifestation of diseases concerning an individual or a population (Rumsfeld 2002), or it can be a multidimensional concept which requires multiple indicators and methodologies for an adequate measurement (Madans and Webster 2015). Several different indicators of health can be tackled with analysis as parasitism, immunological response etc. Among the indicators: morphometrics, parasitism, and white blood cells (WBC) were the destined parameters, of the current study, in order to quantify the health status of sampled individuals.

Accordingly, some hypotheses can be formulated. First, we assume that eumelanin expression influences the individual's health status and we expect a higher number of blood parasites in darker individuals. In addition, we predicted that the number of leukocytes could possibly be greater in dark morphs than in lighter ones considering that they are supposed to have more parasites. In fact, behavioral differences in individuals with different colors can also strongly influence their probability of encountering parasites (Combes 2001). Darker individuals are generally more dominant, and could have a higher propensity to live in groups. This is probably because of pleiotropic effects of the melanocortin system (Karell et al. 2011). Due to parasite exposure, the behavioral differences between morphs might have influential consequences on the overall health of the individual or the population. In addition, we relied on the study of Gasparini et al. (2009) who attested that darker morphs of the Tawny Owl (Strix aluco) are more parasitized and have a better immunity, even if it was not in line with Jacquin et al. (2011) who demonstrated that hemoparasites were independent of melanism. However, we must consider that the abovementioned studies were carried out in European temperate regions, while this study concerns an urban site located in humid climate of North Africa (N. Algeria). These differences in environmental conditions of study areas are expected to influence differently the results, emphasizing once again the importance and originality of this study to the region.

As to morphometrics, they can be considered as the characterization of biologically relevant patterns and forms in ways that allow their quantitative handling (Oxnard 1978). Morphometric approaches facilitate the 
analysis of quantitative variation in form. Few studies have detailed morphometric parameters, and even less its relationship with immunity. Gilot-Fromont et al. (2012) have measured the bodyweight of the Roe Deer (Capreolus capreolus) and correlated it with the level of WBC so as to test the dependability of the immune phenotype on body condition in large mammals. The results demonstrated that the immune phenotype varied with body condition. Further, the individuals living in a population with high resources and having high body condition showed high scores of innate immunity; however, this is insufficient given that only one morphometric measurement was taken into consideration. Therefore, exposures to parasites and stress have to be thoroughly investigated. This is to obtain a better understanding of the determinants of immunity. Concerning birds, Krause et al. (2017) used Zebra Finches (Taeniopygia guttata) as a model system in order to evaluate whether life-history traits such as adult body condition (expressed as the ratio of body mass to tarsus length) and reproductive investment could be influenced by plumage morph. They indicated that white birds were significantly lighter and had lower body condition compared to wild-type birds. It also showed the MBC differences in adult individual associations.

For all the statements mentioned above, the measurement of the bodyweight and its relation to the immunity is important. However, based on the previous attained data and the intelligible vitality of morphometric evidence, we concluded that collecting the maximum amount of morphometric data on individuals is the basis in future researches. Some studies already did so. For instance, the multiple morphometric measures taken by Kolomak et al. (2019) were, likewise, used to better understand biological processes that occur in the parasitized individuals. In our case, the fact of having these parameters in our possession allowed us to establish statistical analyses by correlating morphometrics to $\mathrm{MBC}$. Indeed, a recent study showed a very large variation of morphological and color patterns concerning the Little Owl (Athene noctua), demonstrating the interest of morphological measurements (Pellegrino et al. 2020). The number of leukocytes was assessed from pigeon blood samples and related to individual MBCs through a statistical modeling approach. In summary, this study investigated biological trait (morphometry, parasitism and hematological parameters) differences in urban Feral Pigeons and their relationships with plumage MBC.

\section{Methods}

\section{Study area}

This study was conducted in the city of Annaba, the third largest city in Algeria with a population of about 464,740 (2019 census). The province "Wilaya" of Annaba is located in the extreme northeast of Algeria (longitude: $7.76^{\circ} \mathrm{E}$, latitude: $36.899^{\circ} \mathrm{N}$ ), $600 \mathrm{~km}$ east of the capital Algiers (Fig. 1). The climate is Mediterranean humid with rainfall varying between 650 and $1000 \mathrm{~mm} /$ year. According to Köppen's climatic classification, the region falls with the class $\mathrm{BSk}(\mathrm{B}=$ arid climate, $\mathrm{S}=$ steppe, $\mathrm{k}=$ cold $)$. The De Martonne's aridity index $=22$, indicating a typical Mediterranean climate, whereas Budyko's classification shows a "Steppe" climate type where Budyko's radiation index of dryness $=2.033$ and Budyko's evaporation is estimated to $552 \mathrm{~mm} /$ year. The monthly average temperature ranges between $11{ }^{\circ} \mathrm{C}$ and $25{ }^{\circ} \mathrm{C}$, where January is the coldest month (minimum temperature $=7.8{ }^{\circ} \mathrm{C}$ ) and August is the hottest month (maximum temperature $=29.7^{\circ} \mathrm{C}$ ) (Belabed et al. 2017). Annaba city is bordered in the north and west by the Massif of Edough; the alluvial plain of the Seybouse Wadi to the south, and the Mediterranean Sea to the east.

\section{Data collection}

Feral Pigeons were caught in one site, a building roof situated in the heart of downtown, to which we had access very early in the morning each weekend. We used trapdoor traps, which have proven to be the most efficient technique after many tries. Captured individuals were marked with a ring to make sure there would be only a single test for each pigeon. Thirty free-living adult pigeons $(N=30)$, aged at least one-year-old were captured. During the experiment, we tried to expose pigeons to as little stress as possible. Pigeons were put in large individual cages and exposed to natural light; ensuring that the process was performed as quickly as possible to avoid stressing the animal. This effect was concluded by Davis et al. (2008). The latter demonstrated that the WBC count could change in a very short period of $30 \mathrm{~min}$ if the individual was stressed. This latter was based on the previous studies on the hematological aspect of the same species. The first one was from Graczyk et al. (1994) who developed a procedure for the extraction of Haemoproteus columbae erythrocytic stages from nucleated red blood cells of Columba livia, and they have also determined the density of parasites according to the protocol of Godfrey et al. (1990) through considering the number of parasitized red blood cells examined. The second one aimed to diagnose experimental and natural Toxoplasma gondii infection to Columba livia by serological, biological, and molecular techniques (de Godoi et al. 2010). The major part of the study focused on 12 individuals. It should be noted that more recently, a study on toe mutilations of pigeons at Paris (Jiguet et al. 2019) focused on the same number of individuals as in this study $(N=30)$. At the end, each individual was released on this same site after having served for measuring the traits below. 

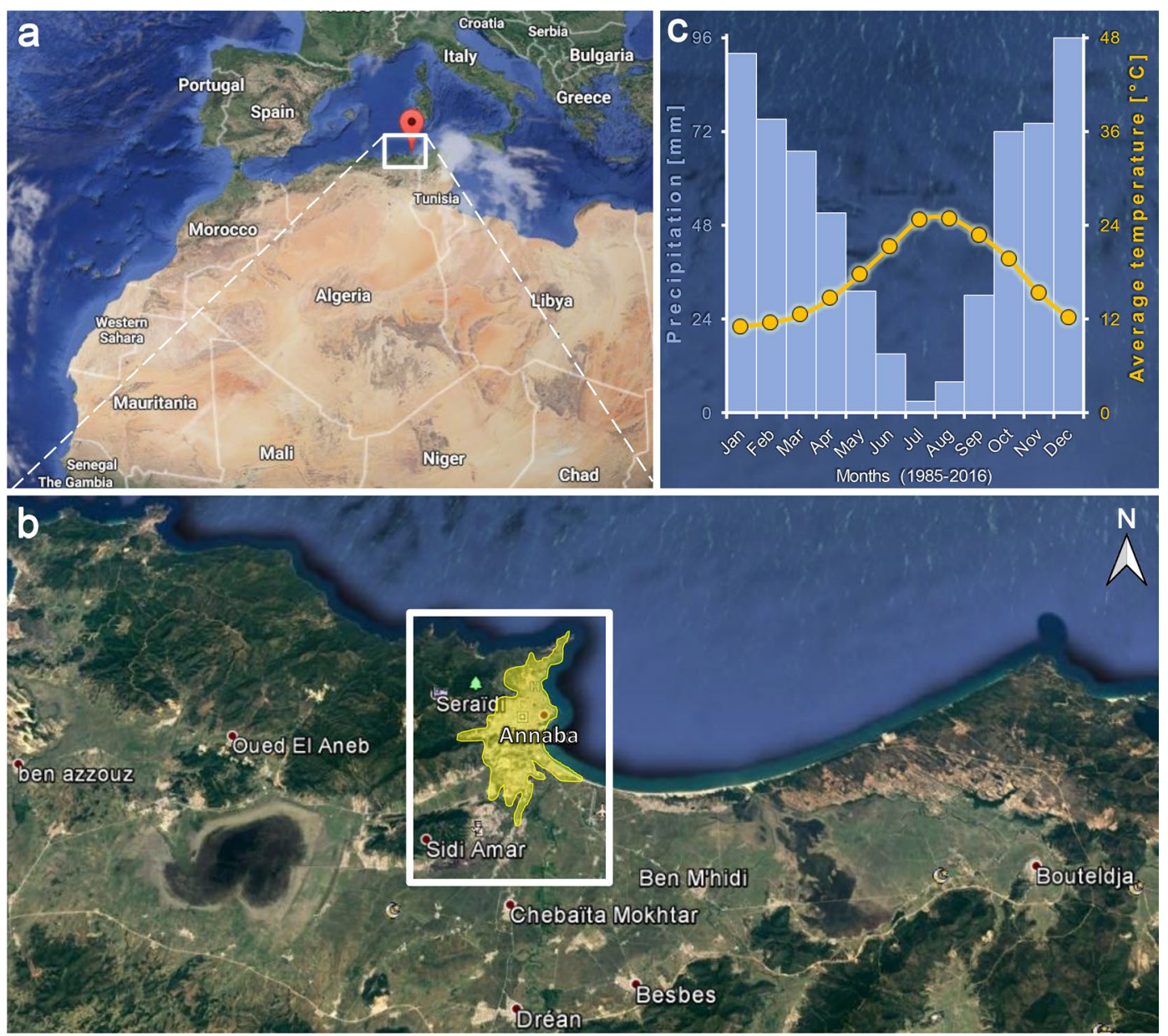

Fig. 1 Map of the study area, the city of Annaba, in northeastern Algeria (a). Urban environments of Annaba City are represented in transparent yellow (b). Upper right plot (c) is the ombrothermic diagram of Guassen with monthly mean temperatures and precipitation are means of long-term meteorological data (1985-2016)

\section{Morphometric parameters}

A series of morphological measurements (Eck et al. 2011) was carried out, including the following traits: body weight was measured using a digital scale (precision $=0.1 \mathrm{~g}$ ). Length of the tarsometatarsus measured as the length from the inner bend of the tibiotarsal articulation to the base of the toes, with the shank of the bird is exposed. In most cases the tarsometatarsus is held bent but in some cases it may be measured on the length of this bone. Length of the phalanx "length of toe" measured ventrally on the foot gently stretched out using sliding calipers. The total length, between the tip of the bill and the tip of the tail, was measured by turning the bird on its back and flattening out the head and neck gently and then measuring the length (Rasmussen and Anderton 2005), although the accuracy of this measure may be questionable because of the difficulty of its realization (Brazil 2009). Length and width of the bill were measured using a plastic caliper because this area is vulnerable. Culmen: the upper mandible of the bill is referred to as the "culmen", this measurement was taken using a sliding caliper with one jaw at the tip of the upper mandible and the other at the base of the first feathers (Borras et al. 2000). Length of folded wing: also called wing chord, the measurement is taken with the wing bent at a $90^{\circ}$ angle, starting with the most noticeable point of the wrist joint to the most prominent point of the longest primary feather. Length of stretched wing: as indicated by its name, the wing is taut and measured at both ends. Length of fifth primary: feather primaries are connected to the manus, these are the longest and narrowest of the remiges, the 5 th was measured at both ends.

\section{Determination of plumage melanin-based coloration}

Color variation in Feral Pigeons is due to the deposition of two different types of melanin pigments: black 
eumelanins and yellow to red phaeomelanins (Haase et al. 1992). This study focused on eumelanic coloration because it is the most widespread in Feral Pigeon populations. Classically, the eumelanic coloration in the Feral Pigeon is visually characterized in five forms (from lightest to darkest): (1) white, (2) blue bar, (3) checker, (4) T-pattern, and (5) spread (Johnston and Janiga 1995). Concerning morphs of pigeon sampled, there were respectively 10 blue bars, 11 checkers, and $9 \mathrm{~T}$-patterns but there were no whites or spreads individuals. For this, it is important to note that phenotypes were scored three times and the results were the same. These forms allowed us to measure continuous variations of black surface proportion compared to the gray of the wings, corresponding to a growing eumelanin deposit in the feathers (Haase et al. 1992). Caught birds were individually photographed to measure the percentage of the black color in the wing surface, which corresponds to eumelanin level that was estimated as number of black pixels/number of white pixels $\times 100$, using the Gimp editing software $v$ 2.8.10 (The GIMP team 2014). This measure has been shown to be a reliable and repeatable estimation of melanin concentrations in pigeon feathers (Chatelain et al. 2016).

\section{Hematological parameters}

Blood samples were collected from each individual using wing venipuncture (Campbell 1995). This procedure is the best method used in most bird species, because many species do not have other blood vessels large enough for venipuncture (Stevens and Ridgway 1966). In recent studies, the methods of blood collection are not very detailed (Kramar et al. 2019) even if this is a common procedures. In the following details, all the steps are listed to ensure optimal reproducibility of the work. When a drop of blood was deposited in the center of the first coverglass, a second was placed on top. Then, the two were pulled apart, resulting in the spread of the blood between the two surfaces (Davidsohn and Henry 1974). For each individual, three drops of blood $(\sim 0.15 \mathrm{~mL})$ were collected (1 drop is approximately equal to $0.05 \mathrm{~mL}$ ). However, only one sample (the clearest one) was used for determining hematologic and parasitic parameters.

Blood smears were processed using the method of Giemsa (Chanarin 1984), which involves the following procedures: under a chemical hood, the smears were arranged (in the same direction) in the staining baskets. After that, the smears were fully immersed in methanol $100 \%$ for $1 \mathrm{~min}$, then the baskets containing the coverglasses were dried at room temperature (Barcia 2007). The Giemsa stain (Ref. GS128, Sigma-Aldrich, Darmstadt, Germany), was prepared by diluting it 15 times in distilled water $(1 \mathrm{v} / 6 \mathrm{v})$. The diluted solution cannot be kept more than a few hours. Once the coverglasses are dry from methanol, samples were immersed for $45 \mathrm{~min}$ into the diluted dye, and then the coverglasses were rinsed abundantly with tap water. Sorbent paper was used to wipe out excess water and completely dry the coverglasses. These coverglasses were stored in boxes with the lid remained open at least for $24 \mathrm{~h}$. The blood smears were analyzed under a light microscope; we have read more than 100 fields of 400 erythrocytes in each slide. However, for two smears, with relatively little blood, approximately 25 fields were read. We counted the parasites, monocytes and granulocytes (e.g. basophils, eosinophils, heterophils) and noted the results on an appropriate sheet following the protocol of Hawkey and Denett (1989).

As a constant reminder, monocytes represent the largest type of WBC. They make a part of the vertebrate innate immune system influencing the process of adaptive immunity. While the granulocytes are characterized by the presence of specific granules in their cytoplasm (Stöppler and Shiel 2014). The role of granulocytes differs depending on their type that includes: (i) basophils are responsible for inflammatory reactions during immune response and also for producing compounds that co-ordinate immune responses (Stone et al. 2010); (ii) eosinophils are responsible for combating multicellular parasites and certain infections in vertebrates (Uhm et al. 2012); and (iii) heterophils also known as neutrophils (in humans), are the most abundant of the three types and the main antibacterial cell agents; they can fight a very wide variety of threats (Ermert et al. 2013). During this study, the same person (HAA) examined all the blood smears (WBC and parasites).

\section{Parasitic variables}

Parasitemia levels represented in this case by the count of Plasmodium spp. were measured from blood smears. The blood was taken at the capture site as quickly as possible so that the pigeon is released. That was done according to the directives of Valkiūnas et al. 2014 未列 出) and for each individual blood sample (see subsection: Hematological parameters). For infected birds, the intensity of parasites was calculated as the number of infected erythrocytes among 10,000 cells from different microscopic fields forming a monolayer (Hawkey and Dennet 1989; Sol et al. 2000). For each bird, a smear was examined on at least 100 microscopic fields per individual. However, if no parasites were observed during the initial scan, to confirm the results, another smear was examined complying with the Tostes et al. (2015) method. In our case, it only happened once $(N=1)$. 


\section{Statistical analysis}

Statistical tests and graph plotting were conducted using the software $R$ version 3.6.3 (R Core Team 2020). Body morphometric traits and hematological parameters of the caught Feral Pigeons were summarized using some descriptive statistics i.e. mean, standard deviation, interquartile range, minimum, median, maximum. Relationships between morphometric traits were tested using Pearson correlations that were plotted as an interactive correlation matrix using the R package "corrplot" version 0.84 (Wei and Simko 2017).

The effects of body morphometrics on the variation of plumage $\mathrm{MBC}$ were tested using linear regressions fitted to generalized linear model (GLM) with Gaussian distribution error and identity link. Each morphometric measurement was fitted separately in a GLM and the effects of all models, whether significant $(P<0.05)$ or not, were considered and discussed. Prior to running tests, one individual with aberrant morphometric scores (i.e. an outlier) was removed of analyses. The outlier was detected by Grubb's test and verified by the $Q-Q$ plot.

The relationships between plumage $\mathrm{MBC}$ and hemoparasite infection (represented by number of infected erythrocytes) and MBC-cell of immunity (e.g. number of monocytes and granulocytes) were analyzed using linear (GLM) and non-linear (generalized additive model, GAM) modeling approaches. GLMs were fitted to Gaussian distribution error and identity link, whereas as MBC was smoothed in Gaussian GAMs. The model fit was assessed using the Akaike's information criterion (AIC) for comparison between models. The selection of model with the best fit was decided based on AIC score, which was the model that expressed the lowest AIC value. When the difference in AIC value between a given model and the best-fit model is greater than 2, that model is not supported. Model implementation and selection were done using the library "nlme" version $3.1-131$ in $R$ (Pinheiro et al. 2017).

\section{Results}

\section{Effects of body morphometrics on melanic-based} coloration

The values of 12 morphological traits measured on adults of Feral Pigeon are reported in Table 1. The generalized linear models testing the effects of body morphometrics on the variation of $\mathrm{MBC}$ demonstrated that body weight $(P=0.003)$, tail length $(P=0.023)$ and body total length $(P=0.040)$ had significant positive effects at a $5 \%$ probability threshold (Table 2; Fig. 2). These 3 body measurements, in the same order stated above, expressed the best fit for explaining the variation of MBC data based on AIC and $R^{2}$ scores. Although the relationship was nonsignificant $(P>0.05)$, there was a negative trend between plumage $\mathrm{MBC}$ with both lengths of folded wing and stretched wing. The other body measurements variables had no significant effect on MBC variation (Table 2). It is noteworthy mentioning that most of these morphological traits were not correlated with each other. Out of 66 correlation tests, only 12 were significant $(P<0.05)$, of which 8 correlations were positive and observed either with body weight or total length (Fig. 3).

\section{Relationship between melanic coloration and hemoparasites}

The plumage $\mathrm{MBC}$ in the sampled Feral Pigeons averaged $30.28 \pm 23.44 \%$ (mean \pm SD) and ranged between

Table.1 Descriptive statistics of body traits measured on free-living Feral Pigeons (Columba livia) in northeastern Algeria

\begin{tabular}{|c|c|c|c|c|c|c|c|}
\hline \multirow[b]{2}{*}{ Morphological traits } & \multicolumn{7}{|c|}{ Descriptive statistics } \\
\hline & Mean & SD & IQR & Min. & Median & Max. & Skewness \\
\hline Body weight (g) & 294.16 & 27.07 & 40.25 & 207.9 & 306.6 & 326.7 & -1.25 \\
\hline Folded wing (cm) & 22.24 & 2.14 & 0.78 & 13.9 & 22.6 & 25.7 & -2.74 \\
\hline Stretched wing $(\mathrm{cm})$ & 26.47 & 2.53 & 1.15 & 16.9 & 27.1 & 28.9 & -2.49 \\
\hline Length of culmen (cm) & 1.38 & 0.15 & 0.20 & 1.1 & 1.4 & 1.6 & -0.14 \\
\hline Bill height (cm) & 1.05 & 0.20 & 0.28 & 0.7 & 1.0 & 1.6 & 0.67 \\
\hline Bill breadth (cm) & 1.20 & 0.10 & 0.20 & 1.0 & 1.2 & 1.4 & 0.07 \\
\hline Total length (cm) & 31.33 & 1.74 & 2.30 & 27.3 & 31.6 & 34.2 & -0.34 \\
\hline Bill length (cm) & 2.22 & 0.16 & 0.20 & 1.9 & 2.2 & 2.6 & 0.34 \\
\hline Length of toes $(\mathrm{cm})$ & 1.12 & 0.12 & 0.10 & 0.9 & 1.1 & 1.3 & -0.28 \\
\hline Tail length (cm) & 13.17 & 0.79 & 1.00 & 11.7 & 13.2 & 14.7 & 0.06 \\
\hline Length of tarsometatarsus (cm) & 2.74 & 0.34 & 0.38 & 2.1 & 2.80 & 3.5 & 0.21 \\
\hline Length of the 5 th primary feather $(\mathrm{cm})$ & 15.22 & 1.08 & 1.23 & 13.2 & 15.4 & 17.1 & -0.38 \\
\hline
\end{tabular}

$S D$ standard deviation, $I Q R$ interquartile range 
Table.2 Parameters of generalized linear models (Gaussian fit and identity link) testing the effects of body morphometric measurements of the Feral Pigeon (Columba livia) on the variation of plumage melanic-based coloration (MBC) at urban environments of Algeria

\begin{tabular}{|c|c|c|c|c|c|}
\hline Model & AIC & $R^{2}$ & $F$-value & $P$-value & Sig. \\
\hline $\mathrm{MBC} \sim$ Body weight & 260.87 & 0.0986 & 10.50 & 0.003 & $* *$ \\
\hline $\mathrm{MBC} \sim$ Tail length & 264.77 & 0.1713 & 5.78 & 0.023 & * \\
\hline MBC Total length & 265.81 & 0.1423 & 4.63 & 0.040 & * \\
\hline $\mathrm{MBC} \sim$ Bill height & 266.89 & 0.0796 & 3.47 & 0.073 & ns \\
\hline $\mathrm{MBC} \sim$ Bill length & 267.97 & 0.0635 & 2.36 & 0.136 & ns \\
\hline $\begin{array}{l}\mathrm{MBC} \sim \text { Length of primary } \\
\text { feather }\end{array}$ & 268.30 & 0.0326 & 2.03 & 0.165 & ns \\
\hline $\mathrm{MBC} \sim$ Bill breadth & 269.43 & 0.0525 & 0.92 & 0.347 & ns \\
\hline $\mathrm{MBC} \sim$ Stretched wing & 269.71 & 0.0171 & 0.66 & 0.425 & ns \\
\hline MBC Culmen & 269.92 & 0.0119 & 0.45 & 0.507 & ns \\
\hline MBC Folded wing & 270.02 & 0.0084 & 0.36 & 0.554 & ns \\
\hline $\mathrm{MBC} \sim$ Length of toes & 270.28 & 0.0033 & 0.11 & 0.743 & ns \\
\hline MBC Tarsometatarsus & 270.33 & 0.0006 & 0.07 & 0.794 & ns \\
\hline
\end{tabular}

AIC Akaike's information criterion, $R^{2}$ : Nagelkerke pseudo R-squared, AIC and $R^{2}$ are used as measures of the goodness-of-fit of each model, $F$ - and $P$-values are results of Type-III test ANOVA applied to each GLM, Sig.: statistical significance, ${ }^{* *} P<0.01,{ }^{*} P \leq 0.05$, ns: $P>0.05$ )

0.3 and $74.8 \%$. The number of infected erythrocytes, monocytes and granulocytes were counted on blood smears that showed that, with parasitized erythrocytes averaged $65.77 \pm 57.32$ cells $/ 50 \mu \mathrm{L}$ blood per individual (range: 0-52). The GLM testing the relationship between MBC and hemoparasites showed that the number of infected erythrocytes observed in free-living Feral Pigeons increased slightly with the increase in $\mathrm{MBC}$ scores (Table 3), however this relationship was found to be non-significant $(P>0.05)$. In addition, this relationship seemed to not fit a linear trend following the range of MBC (Fig. 4). The Gaussian GAM, with 13.9\% of deviance explained, revealed that this relationship had a nonlinear trend. GAM with smoothing MBS observations in relation to hemoparasites was the model with best fit $(\mathrm{AIC}=330.66)$ compared to GLM $(\mathrm{AIC}=332.72)$. The GAM model indicated a positive effect of $M B C$ on the variation of the number of infected erythrocytes (Table 3). First, individuals with low levels of MBC $(<20 \%)$ showed a negative effect of plumage MBC on the number of infected erythrocytes, then the relationship between $\mathrm{MBC}$ and infected erythrocytes took a positive trend in pigeons with high scores of MBC $20-75 \%$ (Fig. 4).

\section{Effects of plumage melanin level on hematological parameters}

Quantified in blood smears, the mean number of monocytes was $8.03 \pm 5.16$ cells $/ 50 \mu \mathrm{L}$ (range: $3-24$ ) and granulocytes was $18.37 \pm 11.3$ cells $/ 50 \mu \mathrm{L}$ (range: $1-50$ ). GLMs revealed that the immune responses did not follow a linear trend to express the relationship between $\mathrm{MBC}$ and the number of monocytes and granulocytes. Indeed, no significant effects were detected between $\mathrm{MBC}$ scores and the variation of monocytes and granulocytes (GLM: P>0.05) (Fig. 5; Table 4). GAMs showed non-linear relationships between $\mathrm{MBC}$ and immune responses. GAMs explained $8.13 \%$ and $6.22 \%$ of deviance for monocytes and granulocytes, respectively. MBC seemed to differently influence the variation of monocyte and granulocyte counts in infected pigeons. The trend looked similar to a bell-shaped curve. First, the number

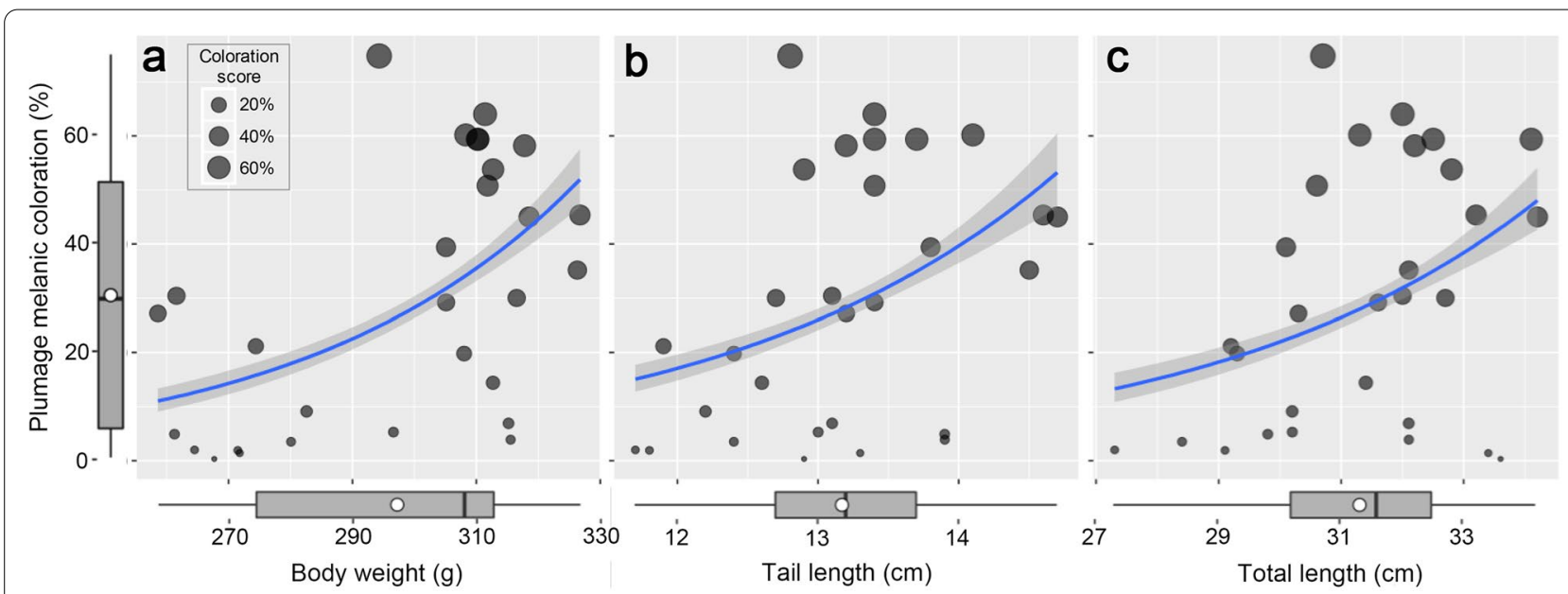

Fig. 2 Relationship between plumage melanic-based coloration and body weight (a), tail length (b) and total length (c) of the Feral Pigeon (Columba livia) at urban environments of Algeria. The solid lines represent regressions obtained by binomial GLM fit with confidence regions in light grey. Solid white circles within side boxplots indicate the average $(N=29$ individuals) 


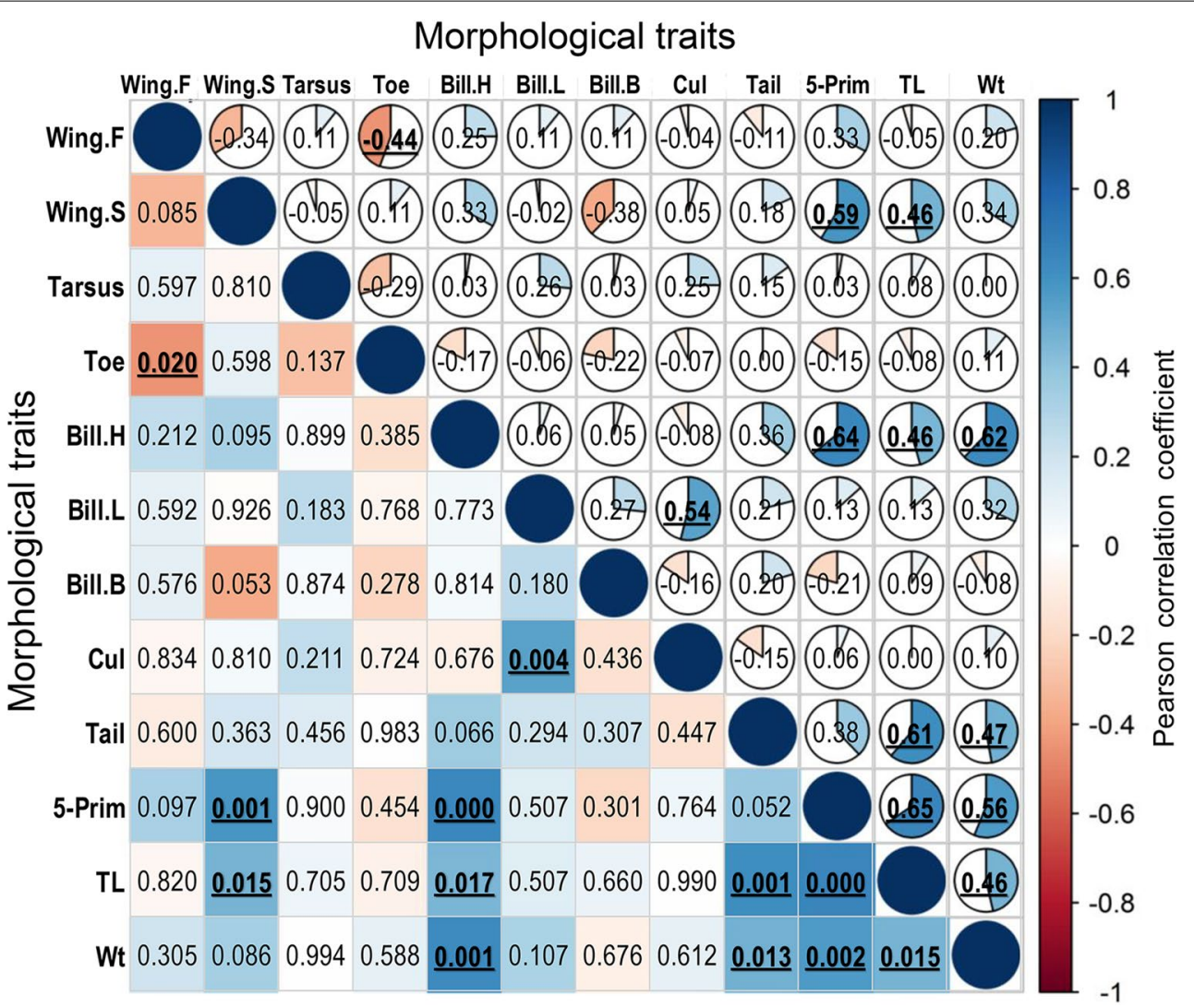

Fig. 3 Correlation matrix applied for body traits of study Feral Pigeons (Columba livia) in northeastern Algeria ( $N=30$ individuals). Values of Pearson correlation tests are given within pie charts as the correlation coefficient (above diagonal) and $P$-value (under diagonal). A significant correlation $(P<0.05)$ is indicated by underlined boldface font. Wing.F length of folded wing $(\mathrm{cm})$, Wing.S length of stretched wing $(\mathrm{cm})$, Tarsus: length of tarsometatarsus $(\mathrm{cm})$, Toe length of toes $(\mathrm{cm})$, Bill.H bill height $(\mathrm{cm})$, Bill.L bill length $(\mathrm{cm})$, Bill.B bill breadth $(\mathrm{cm})$, Cul Culmen $(\mathrm{cm})$, Tail tail length $(\mathrm{cm})$, 5-Prim length of 5th primary feather (cm), TL total length $(\mathrm{cm})$, Wt body weight $(\mathrm{g})$

Table.3 Summaries of generalized linear model (GLM) and generalized additive model (GAM) testing the relationship between plumage melanic-based coloration and hemoparasite infection (number of infected erythrocytes) in free-living Feral Pigeons (Columba livia) in urban environments

\begin{tabular}{lccccc}
\hline Coefficient & Est & SE & t-value & $P$ & Sig \\
\hline Gaussian GLM & with identity & $(\mathrm{AIC}=332.72$, & $\Delta \mathrm{AIC}=2.06)$ & & \\
Intercept & 58.14 & 17.492 & 3.32 & 0.002 & $* *$ \\
MBC & 0.25 & 0.460 & 0.55 & 0.588 & $\mathrm{~ns}$ \\
GAM (deviance explained $=13.9 \%, \mathrm{AIC}=330.66, \Delta \mathrm{AIC}=0)$ & \\
Intercept & 65.77 & 10.070 & 6.53 & $<0.001$ & $* * *$ \\
Smooth term & Edf & Ref. df & $F$ & $P$ & Sig \\
Smooth (MBC) & 2.05 & 2.56 & 1.40 & 0.336 & $\mathrm{~ns}$ \\
\hline
\end{tabular}

AIC Akaike's information criterion, $\triangle A I C$ difference between the AICs of the tested model compared to the model with the best fit, Est. estimate, $S E$ standard error, $P$ probability value, Sig. statistical significance, ${ }^{* * *} P<0.001,{ }^{* *} P<0.01$, ns: $P>0.05$, Edf estimated degrees of freedom, Ref. $d f$ reference degrees of freedom, FF-statistics of both monocytes and granulocytes increased with the increase in $\mathrm{MBC}$ levels in individuals with light plumage coloration $(\mathrm{MBC}<30 \%$ for monocytes and $\mathrm{MBC}<40 \%$ for granulocytes). Beyond these scores, cellular immune responses decreased when MBC increased.

\section{Discussion}

This correlative bird study is one of only a few such studies that have been conducted in North Africa. Although there are many studies concerning the avifauna, urban habitats and the interactions between humans and wildlife are still very rare and understudied in Algeria. In fact, we still discover species that were believed not existent in our ecosystem (Farhi et al. 2020). This study analyzed the relationships that may exist between body morphometrics on plumage $\mathrm{MBC}$ levels on the one hand, and how plumage coloration can indicate the health status of wild and/or naturalized urban animals. In general, the characterization of individuals and the measurement of intra-population 


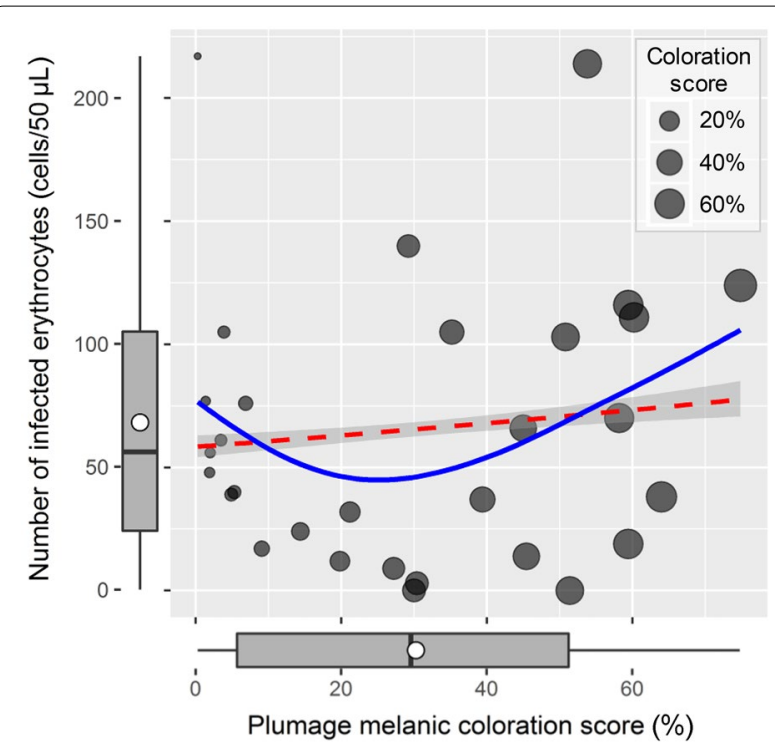

Fig. 4 Relationship between plumage melanic-based coloration and number of infected erythrocytes in free-living Feral Pigeons (Columba livia) in urban environments of Algeria. The dashed red line is a linear regression with a Poisson GLM fit, with 95\% confidence region in light grey. The blue solid line represents the predicted curve from a generalized additive model (GAM) with Poisson error distribution. Solid white circles within side boxplots indicate the average (sample size $=30$ individuals)

variability is accompanied by a series of biometric surveys (Jarry and Baillon 1991). The current study showed significant correlation between $\mathrm{MBC}$ and bird body weight. Our findings suggest that for urban Feral Pigeons in Annaba, the heavier the individual, the higher the plumage coloration score.

True polymorphism and geographical variation in coloration are expected to affect population processes and response to environmental changes differently. For example, Obukhova (2001) noted that darker eumelanin morphs were positively correlated with high densities in both space and time. In our study site, the population density is particularly high (one of the reasons that made us choose this site) and we expected the pigeons to be darker than what we found. In urbanized environments, darker $\mathrm{MBC}$ could therefore reflect an adaptation to high population density, which could lead consequently to a selective advantage (Récapet et al. 2013).

In our results, one of the most interesting points concerns the fact that body weight was positively correlated with $\mathrm{MBC}$, which has not been clearly established by previous studies. The relationships of MBC with tail length and total length can be also regarded as key predictors of MBC changes. This introduces researches to interesting perspectives. The rest of body morphological traits may not be directly related to the plumage $\mathrm{MBC}$ but much

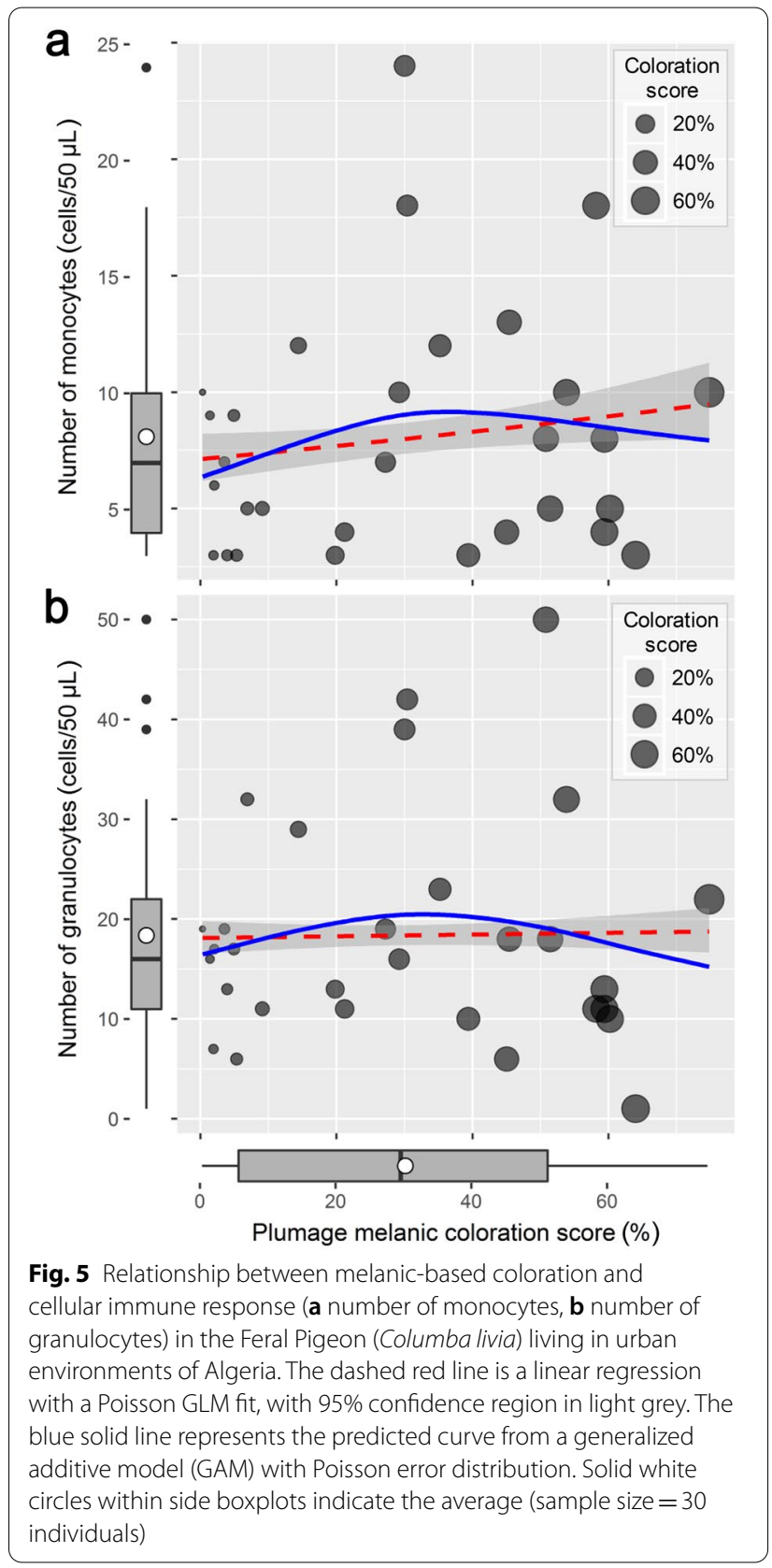

more to trophic and anthropogenic resources of the surrounding areas.

Concerning parasitism, haemosporidian infections caused by protozoa of the genera Plasmodium and Haemoproteus can be considered among the causes of population decline or extinction of some bird species worldwide (Samuel et al. 2015). Nonetheless, the potential role of parasitic diseases in the decline of bird populations has not been fully addressed and understood (Martínez et al. 2015). Though the visual inspection of blood smears generally underestimates blood parasite 
Table.4 Comparison between generalized linear model (GLM) and generalized additive model (GAM) testing the effects of plumage melanic coloration levels on the variation of monocyte and granulocyte numbers in infected Feral Pigeons (Columba livia) in urban environments

\begin{tabular}{|c|c|c|c|c|c|}
\hline \multicolumn{6}{|c|}{ Numbers of monocytes $\sim$ melanic-based coloration } \\
\hline Coefficient & Est. & SE & $t$-value & $P$ & Sig. \\
\hline \multicolumn{6}{|c|}{ Gaussian GLM with identity link (AIC $=187.93, \triangle \mathrm{AIC}=0.67)$} \\
\hline Intercept & 7.10 & 1.566 & 4.53 & $<0.001$ & $* * *$ \\
\hline $\mathrm{MBC}$ & 0.03 & 0.041 & 0.75 & 0.459 & ns \\
\hline \multicolumn{6}{|c|}{ GAM (Deviance explained $=8.13 \%, \mathrm{AIC}=187.26, \triangle \mathrm{AIC}=0$ ) } \\
\hline Intercept & 8.03 & 0.929 & 8.65 & $<0.001$ & $* * *$ \\
\hline Smooth term & edf & Ref. df & F & $P$ & Sig. \\
\hline Smooth (MBC) & 1.64 & 2.03 & 0.83 & 0.458 & ns \\
\hline \multicolumn{6}{|c|}{ Numbers of granulocytes $\sim$ melanic-based coloration } \\
\hline Coefficient & Est. & SE & $t$-value & $P$ & Sig. \\
\hline \multicolumn{6}{|c|}{ Gaussian GLM with identity link $(\mathrm{AIC}=235.58, \triangle \mathrm{AIC}=0.73)$} \\
\hline Intercept & 18.10 & 3.465 & 5.22 & $<0.001$ & $* * *$ \\
\hline MBC & 0.01 & 0.091 & 0.10 & 0.925 & ns \\
\hline \multicolumn{6}{|c|}{ GAM (Deviance explained $=6.22 \%, \mathrm{AIC}=234.85, \triangle \mathrm{AIC}=0$ ) } \\
\hline Intercept & 18.37 & 2.055 & 8.94 & $<0.001$ & $* * *$ \\
\hline Smooth term & edf & Ref. df & F & $P$ & Sig. \\
\hline Smooth (MBC) & 1.59 & 1.97 & 0.54 & 0.582 & ns \\
\hline
\end{tabular}

AIC Akaike's information criterion, $\triangle A I C$ difference between the AICs of the tested model compared to the model with the best fit, Est. estimate, SE standard error, $P$ probability value, Sig. statistical significance, ${ }^{* * *} P<0.001, \mathrm{~ns}: P>0.05$, Edf estimated degrees of freedom, Ref. df: reference degrees of freedom, F: F-statistics

prevalence and intensity compared to PCR screening, it can provide reliable information for comparisons between individuals of some species (Fallon and Ricklefs 2008). In our case, blood slides have been rescored three times and the results were much the same. Unfortunately, some chronic infections cannot be identified using smears from some species. It would have been interesting to use other diagnostic tools. In their work, Ishtiaq et al. (2017) compared the method-specific estimates of the detection probability to assess the relative performance of screening strategies. It was demonstrated that the diagnostic sensitivities vary in terms of methods, laboratories, and study areas; therefore, the occurrence of false negatives is critical to allow the quality comparisons of prevalence among studies. We cannot neglect the fact that urbanization has consequences on parasitism and disease transmission between wildlife and humans (Comer et al. 2001). Some studies showed a decrease in the number of parasites in urban individuals compared to rural ones, which can be related to the poor quality of urban habitats for vectors (Gregoire et al. 2002; Evans et al. 2009). In addition, several studies demonstrated that urbanization strongly influences exposure to parasites and host resistance, but showed that the pathway and intensity of these effects are host species-specific and depends on the considered parasite (Luniak 2004; Bradley and Alitzer 2007; Evans et al. 2009 未列出). Besides, characteristics of both individuals (described as animal personality and behavioral traits including aggressiveness and escape distance (Barber and Dingemanse 2010)) and the city (summarized as density, diversity, and complexity (Vlahov et al. 2007)) are determinants of the relationship between level of parasitism and urbanization. Addressing these relationships has fundamental implications because they provide a better understanding of the role of parasites in the evolution and adaptation of urban-adapted and urban-exploiter species (Pollack et al. 2017).

As expected, our findings revealed a positive relationship between the level of MBC and the number of blood parasites, which means that darker morphs had more parasites. This is contradictory to Jacquin et al. (2011) that studied 195 free-living Feral Pigeons in Paris and correlated $\mathrm{MBC}$ with parasitism quantified in blood smears. Their results suggested that all morphs could be similarly exposed to parasites despite a probable spatial heterogeneity in parasite exposure in urban environments. Dark morphs would indeed have lower parasite intensity because they have a better immunocompetence than paler ones due to pleiotropic effects of melanin genes and not because they were differently exposed to parasites. Their data point out the potential role of parasitism in the maintenance of color polymorphism in 
natural populations by suggesting a link between natural selection on parasite resistance and the expression of melanin-based coloration in pigeons. The same author studied later a sample of 488 individuals in Paris and examined how differently colored genotypes responded to urbanization by comparing their blood parasite prevalence and parasite load along an urbanization gradient (Jacquin et al. 2013a). This time, their results suggested that paler morphs were less parasitized than darker ones in moderately urbanized habitats, but their parasite prevalence increased with urbanization. In contrast, dark morphs had similar parasite prevalence along the urbanization gradient. This indicates that paler morphs performed better than dark morphs in moderately urbanized areas but were negatively affected by increasing urbanization. In contrast, darker morphs performed equally in all environments. All these studies deserve to be discussed in more detail since some are in agreement with the standard knowledge while others are not. However, at low levels of $\mathrm{MBC}$, the GAM showed a negative trend demonstrating that when $\mathrm{MBC}$ varies from 0 to $20 \%$, approximately, the number of parasites decreases. This suggests that apart from genotypic variation, other variables may also affect color changes in relation to social context and parasitic infection (Miller and Brooks 2005). This is particularly true in urban environments that remain quite complex and still slightly investigated.

According to Blanchet et al. (2009), parasitism is determined by both physiological responses and behavioral defenses. So, it is necessary to consider multiple traits and to discriminate between different types of parasites to infer direct, indirect and correlative effects of $\mathrm{MBC}$ individual variation on parasitism. The reasons can also be related to either the strategies of species life history or the severity of urban environments. All these relationships remain correlative; and it is still difficult to fully understand the factors related to urbanization and those determining the variation in species life history traits (Aouissi 2016; Aouissi et al. 2021). Indeed, many factors such as environmental stresses related to human activities (e.g. chemical pollution, noise, artificial light pollution, and human presence), parasites, and food characteristics co-vary with urbanization as well as with social and economic conditions, which are likely quite different between rural and urban environments (Belabed et al. 2017).

However, the relationship between coloration and parasite load probably depends on other environmental stressors that vary along disturbance gradients (Côte et al. 2018). For example, some studies have shown that immunity and behavior are highly sensitive to biotic and abiotic stressors (Emaresi et al. 2016). Moreover, differently colored individuals often differ in their responsiveness to stressors. For instance, Jacquin et al. (2013a) noted that dark Feral Pigeons are less infected by hemoparasites compared to pale individuals, but only in heavily urbanized conditions. In addition, $\mathrm{MBC}$ and resistance to oxidative stress are tightly linked (Galván and Solano 2015), with individual variation in stress responsiveness is reflected by MBC (Kittilsen et al. 2009).

Although the underpinning environmental factors remain difficult to identify, recent studies outline the increasing role of oxidative stress and also pollutants. Indeed, Chatelain et al. (2014) investigated higher resistance of darker birds to pollutants. For instance, they stated that since melanin pigments have detoxifying properties, darker people are more resistant to heavy metal contamination and the relationship between MBC and immunity thus depends on trace metal contamination (Chatelain et al. 2016).

In our case, it is hard to determine which variable would have the most impact in the relationship between $\mathrm{MBC}$ and parasitism, specifically regarding human activities because in our area all these factors are present in a non-negligible way and their impact have almost never been studied previously (Aouissi 2016). It is difficult to dissociate the different selection pressures associated with urban area, which suggests the necessity of implementing a complementary experimental approach with the manipulation of environmental factors under controlled conditions (Jacquin et al. 2011, 2012).

The link between MBC and immunity status seems very variable and depends on the specific component of the immune system, the considered species and the environmental conditions. Eumelanin-based coloration does not seem to reflect a better resistance to parasites in most of the cases. However, it could instead reflect alternative responses against parasitism (Gasparini et al. 2009). Therefore, it is likely that the different morphs are not exposed in the same way to parasites (Jacquin et al. 2013b). For instance, paler pigeons could be less exposed to parasites compared to darker ones in less urbanized areas because of the exploitation of different microhabitats as has been studied in the case of the Tawny Owl (Strix aluco; Galeotti and Sacchi 2003) or different behaviors that would affect exposure to malaria vectors (Hart 1997). It could also be that the different morphs have differences in parasite resistance related to variations in immune quality. Another possibility is that darker melanin morphs could be more resistant to endoparasites such as blood parasites but more susceptible to ectoparasites (Chakarov et al. 2008).

Concerning hematology and cellular response, there are fewer studies that have investigated the link between $\mathrm{MBC}$ and immunity in vertebrates compared to studies that related MBC to other traits (Ducrest et al. 2008; 
Dreiss et al. 2010). This study indicated a positive trend between $\mathrm{MBC}$ and the intensity of immunity, represented here by counts of monocytes and granulocytes. The trend seems to be significant from a particular threshold, e.g. $30 \%$ for monocytes and $40 \%$ for granulocytes. As for parasites, it is difficult to explain the results concretely, given that several factors co-vary. A high number of immunological cells is generally a good indicator of an infection. Thus, according to Leclaire et al. (2019), the high number of parasites confirms these comments, even if values are relative, and could also just indicated an adequate baseline of cells.

According to Gasparini et al. (2009) and Roulin et al. (2000, 2001), darker morphs are able to produce more antibodies to better control the proliferation of ectoparasites, and better withstand oxidative stress (Galván and Solano 2009). These co-variations could be due to the anti-inflammatory effects of melanocortins, which could be the source of a physiological link between immunity and color via pleiotropic interactions of immunity genes (Ducrest et al. 2008). However, Galeotti and Sacchi (2003) with their exposure hypothesis stated that these co-variations are also likely to be explained by different exposure levels between morphs if they exploit different microenvironments in terms of parasite density. Several studies have claimed that individuals with darker $\mathrm{MBC}$ reflect a higher quality immune system compared to lighter individuals (Moreno and Møller 2006; Roulin et al. 2011). Indeed, in the Feral Pigeon, darker individuals have a better cellular response compared to conspecifics with lighter plumage. Although the $\mathrm{MBC}$ is positively correlated with cellular immunity in Feral Pigeon, patterns of this relationship might be different for other bird species (Jacquin et al. 2011, 2013a).

\section{Conclusions}

This urban ornithological study, based on a correlative approach, sheds light on the relationship between plumage melanin-based coloration, body morphological characteristics, and some hematological parameters reflecting health status. Our findings demonstrated that the body weight, tail length and total length were correlated positively with MBC. The variation of hemoparasites vs. MBC indicated an interesting trend where darker morphs had more parasites compared to lighter ones. Even if this is not always the case, an increase in the number of WBC can be considered as a signal infection (George and Panos 2005). This might justify our situation, given that the number of monocytes and granulocytes increased in individuals with high $\mathrm{MBC}$ scores (from a certain $\mathrm{MBC}$ threshold). As for any ecological study carried out in urban environments, the presence of some co-variations may add without a doubt, difficulty and unpredictability of this kind of studies. This study opened interesting horizons about the adaptations of feral birds to urban environments. As the size of our sample remains relatively small, further studies are more than needed to have more consistent data on the different mechanisms about the relationships between MBC and various body and life traits. This correlative study was also done in a single city, thus extending the study area to several cities in the future may help to clarify some of the detected relationships, especially in North Africa and Middle-East regions, for which data remain almost non-existent.

\section{Acknowledgements \\ Many thanks are addressed to Pr. Julien Gasparini and the IEES - UPMC (Paris) for providing good working conditions to HAA. Mrs. Warda Aouissi and Mr. Salah-Eddine Aouissi helped conducting this study. Dr. Ibrahim Belabed and Mr. Walid Makrouf assisted in field work with specimen handling. Dr. Saifi Merdas helped with drawing the map of the study area. The anonymous reviewers' comments improved the manuscript.}

\section{Authors' contributions}

$\mathrm{HAA}$ and $\mathrm{HC}$ conceived and designed the study. HAA conducted the experiment and the field research. $\mathrm{HC}$ analyzed the data and conceived the article. HAA, HC, MA, AG drafted and revised the manuscript. ZB and YF supervised the study. All authors read and approved the final manuscript.

\section{Funding}

This study was supported by the DGRSDT and MESRS (Ministry of Higher Education and Scientific Research of Algeria).

\section{Availability of data and materials}

The dataset generated and/or analyzed during the current study is available in the Figshare repository, https://doi.org/10.6084/m9.figshare.13623893.

\section{Declarations}

\section{Ethics approval and consent to participate}

All procedures were approved by the CRSTRA and Badji-Mokhtar Annaba University who have authorization from the ministry and in consent with the IEES, Paris.

Consent for publication

Not applicable.

\section{Competing interests}

The authors declare that they have no competing interest.

\section{Author details}

${ }^{1}$ Scientific and Technical Research Center on Arid Regions (CRSTRA), 07000 Biskra, Algeria. ${ }^{2}$ Faculty of Sciences, Department of Biology, BadjiMokhtar Annaba University, 23000 Annaba, Algeria. ${ }^{3}$ Environmental Research Center (CRE), Badji-Mokhtar Annaba University, 23000 Annaba, Algeria. ${ }^{4}$ Department of Nature and Life Sciences, Faculty of Exact Sciences and Nature and Life Sciences, University of Larbi Tebessi, 12002 Tebessa, Algeria. ${ }^{5}$ Laboratory of Natural Resources and Management of Sensitive Environments 'RNAMS', University of Larbi Ben M'hidi, 04000 Oum-El-Bouaghi, Algeria.

Received: 19 October 2020 Accepted: 2 September 2021

Published online: 14 September 2021

\section{References}

Almasi B, Jenni L, Jenni-Eiermann S, Roulin A. Regulation of stress response is heritable and functionally linked to melanin-based coloration. J Evol Biol. 2010;23:987-96. 
Aouissi HA, Belabed Al, Bouslama Z. Doves' mapping and inventory into the urban sites of Annaba (Northeastern of Algeria). Adv Environ Biol. 2015;12:328-38.

Aouissi HA, Gasparini J, Belabed Al, Bouslama Z. Impact of greenspaces in city on avian species richness and abundance in Northern Africa. CR Biol. 2017;340:394-400.

Aouissi HA, Petrişor Al, Ababsa M, Boștenaru-Dan M, Tourki M, Bouslama Z. Influence of land use on avian diversity in North African urban environments. Land. 2021:10:434.

Aouissi HA. Écologie des espèces aviaires dans le tissu urbain de la ville de Annaba. Doctoral Thesis. Annaba: University of Annaba; 2016.

Barber I, Dingemanse NJ. Parasitism and the evolutionary ecology of animal personality. Philos Trans R Soc B. 2010;365:4077-88.

Barcia JJ. The Giemsa stain: its history and applications. Int J Surg Pathol. 2007;15:292-6.

Belabed Al, Aouissi HA, Zediri H, Djemadi I, Driss K, Houhamdi M, et al. The effect of urbanization on the phenotype of the Collared Dove (Streptopelia decaocto) in northeastern Algeria. Bull Inst Sci Rabat. 2013;35:155-64.

Belabed BE, Meddour A, Samraoui B, Chenchouni H. Modeling seasonal and spatial contamination of surface waters and upper sediments with trace metal elements across industrialized urban areas of the Seybouse watershed in North Africa. Environ Monit Assess. 2017;189:265.

Bendjoudi D, Chenchouni H, Doumandji S, Voisin JF. Bird species diversity of the Mitidja Plain (Northern Algeria) with emphasis on the dynamics of invasive and expanding species. Acrocephalus. 2013;34:13-26.

Bendjoudi D, Voisin JF, Doumandji S, Merabet A, Benyounes N, Chenchouni H. Rapid increase in numbers and change of land-use in two expanding Columbidae species (Columba palumbus and Streptopelia decaocto) in Algeria. Avian Res. 2015;6:18.

Berry JL. Urbanization. The earth as transformed by human action. In: Turner II BL, Clark WC, Kates RW, Richards JF, Mathews JT, Meyer WB, editors. The earth as transformed by human action: global and regional changes in the biosphere over the past 300 years. Cambridge: Cambridge University Press, UK; 1990. p. 103-19.

Blair R. The effects of urban sprawl on birds at multiple levels of biological organization. Ecol Soc. 2004;9:2.

Blanchet S, Méjean L, Bourque JF, Lek S, Thomas F, Marcogliese DJ, et al. Why do parasitized hosts look different? Resolving the "chicken-egg" dilemma. Oecologia. 2009;160:37.

Borras A, Pascual J, Senar JC. What do different bill measures measure and what is the best method to use in granivorous birds? J Field Ornithol. 2000;71:606-11.

Bradley CA, Altizer S. Urbanization and the ecology of wildlife diseases. Trends Ecol Evol. 2007;22:95-102.

Brazil M. Birds of east Asia: China, Taiwan, Korea, Japan, and Russia. Princeton, New Jersey: Princeton University Press; 2009.

Campbell TW. Avian hematology and cytology. 2nd ed. Ames, IA: lowa State University Press; 1995.

Chakarov N, Boerner M, Krüger O. Fitness in common buzzards at the cross-point of opposite melanin-parasite interactions. Funct Ecol. 2008;22:1062-9.

Chanarin I. Hematology: principles and procedures. J Clin Pathol. 1984;37:1419.

Chatelain M, Gasparini J, Frantz A. Do trace metals select for darker birds in urban areas? An experimental exposure to lead and zinc. Glob Chang Biol. 2016;22:2380-91.

Chatelain M, Gasparini J, Jacquin L, Frantz A. The adaptive function of melaninbased plumage coloration to trace metals. Biol Lett. 2014;10:20140164.

Chatelain M, Pessato A, Frantz A, Gasparini J, Leclaire S. Do trace metals influence visual signals? Effects of trace metals on iridescent and melanic feather colouration in the feral pigeon. Oikos. 2017;126:1542-53.

Chedad A, Bendjoudi D, Beladis I, Guezoul O, Chenchouni H. A comprehensive monograph on the ecology and distribution of the House bunting (Emberiza sahari) in Algeria. Front Biogeogr. 2021;13:e47727.

Chenchouni H. Contribution à l'étude de la bio-écologie de la Cigogne blanche (Ciconia ciconia) dans la région de Batna (Nord-est algérien). Doctoral Thesis. Algeria: University of Batna; 2017a.

Chenchouni H. Variation in White Stork (Ciconia ciconia) diet along a climatic gradient and across rural-to-urban landscapes in North Africa. Int J Biometeorol. 2017;61:549-64.
Clavel J, Julliard R, Devictor V. Worldwide decline of specialist species: toward a global functional homogenization? Front Ecol Environ. 2011;9:222-8.

Combes C. Parasitism: the ecology and evolution of intimate interactions. Chicago: University of Chicago Press; 2001.

Comer JA, Paddock CD, Childs JE. Urban zoonoses caused by Bartonella, Coxiella, Ehrlichia, and Rickettsia species. Vector Borne Zoonotic Dis. 2001;1:91-118.

Corbel H, Legros A, Haussy C, Jacquin L, Gasparini J, Karimi B, Frantz A. Stress response varies with plumage colour and local habitat in feral pigeons. J Ornithol. 2016;157:825-37.

Côte J, Boniface A, Blanchet S, Hendry AP, Gasparini J, Jacquin L. Melaninbased coloration and host-parasite interactions under global change. Proc R Soc Lond B Biol. 2018;285:20180285.

Davey JW, Cezard T, Fuentes-Utrilla P, Eland C, Gharbi K, Blaxter ML. Special features of RAD Sequencing data: implications for genotyping. Mol Ecol. 2013;22:3151-64.

Davidsohn I, Henry JB. Clinical diagnosis by laboratory methods. 15th ed. Philadelphia, Pa: W. B. Saunders Co; 1974.

Davis AK, Maney DL, Maerz JC. The use of leukocyte profiles to measure stress in vertebrates: a review for ecologists. Funct Ecol. 2008;22:760-72.

de Godoi FSL, Nishi SM, de Jesus Pena HF, Gennari SM. Toxoplasma gondii: diagnosis of experimental and natural infection in pigeons (Columba livia) by serological, biological and molecular techniques. Rev Bras Parasitol Vet. 2010;19:238-43.

Devictor V, Julliard R, Clavel J, Jiguet F, Lee A, Couvet D. Functional biotic homogenization of bird communities in disturbed landscapes. Glob Ecol Biogeogr. 2008a;17:252-61.

Devictor V, Julliard R, Couvet D, Lee A, Jiguet F. Functional homogenization effect of urbanization on bird communities. Conserv Biol. 2007;21:741-51.

Devictor V, Julliard R, Jiguet F. Distribution of specialist and generalist species along spatial gradients of habitat disturbance and fragmentation. Oikos. 2008b;117:507-14.

Dreiss A, Henry I, Ruppli C, Almasi B, Roulin A. Darker eumelanic barn owls better withstand food depletion through resistance to food deprivation and lower appetite. Oecologia. 2010;164:65-71.

Ducatez S, Giraudeau M, Thébaud C, Jacquin L. Colour polymorphism is associated with lower extinction risk in birds. Glob Chang Biol. 2017:23:3030-9.

Ducrest AL, Keller L, Roulin A. Pleiotropy in the melanocortin system, coloration and behavioural syndromes. Trends Ecol Evol. 2008;23:502-10.

Eck S, Fiebig J, Fiedler W, Heynen I, Nicolai B, Töpfer T, et al. Measuring birds/ vögel vermessen. Germany: Deutsche Ornithologen-Gesellschaft; 2011.

Emaresi G, Henry I, Gonzalez E, Roulin A, Bize P. Sex- and melanism-specific variations in the oxidative status of adult tawny owls in response to manipulated reproductive effort. J Exp Biol. 2016;219:73-9.

Ermert D, Niemiec MJ, Röhm M, Glenthøj A, Borregaard N, Urban CF. Candida albicans escapes from mouse neutrophils. J Leukocyte Biol. 2013;94:223-36.

Evans KL, Gaston KJ, Sharp SP, McGowan A, Simeoni M, Hatchwell BJ. Effects of urbanisation on disease prevalence and age structure in blackbird Turdus merula populations. Oikos. 2009;1 18:774-82.

Fallon SM, Ricklefs RE. Parasitemia in PCR-detected Plasmodium and Haemoproteus infections in birds. J Avian Biol. 2008;39:514-22.

Farhi Y, Aouissi HA, Nouidjem Y, Belhamra M. Spur-winged Lapwing at Djamaa, Algeria, in June 2011. Dutch Birding. 2020;42:186-7.

Fokidis HB, Greiner EC, Deviche P. Interspecific variation in avian blood parasites and haematology associated with urbanization in a desert habitat. J Avian Biol. 2008:39:300-10.

French SS, Fokidis HB, Moore MC. Variation in stress and innate immunity in the tree lizard (Urosaurus ornatus) across an urban-rural gradient. J Comp Physiol B. 2008;178:997-1005.

Gaagai A, Boudoukha A, Boumezbeur A, Benaabidate L. Hydrochemical characterization of surface water in the Babar watershed (Algeria) using environmetric techniques and time series analysis. Int J River Basin Manag. 2017;15:361-72

Galeotti P, Sacchi R. Differential parasitaemia in the tawny owl (Strix aluco): effects of colour morph and habitat. J Zool. 2003;261:91-9.

Galván I, Solano F. Melanin chemistry and the ecology of stress. Physiol Biochem Zool. 2015;88:352-5. 
Galván I, Solano F. The evolution of eu- and pheomelanic traits may respond to an economy of pigments related to environmental oxidative stress. Pigment Cell Melanoma Res. 2009;22:339-42.

Gasparini J, Bize P, Piault R, Wakamatsu K, Blount JD, Ducrest AL, et al. Strength and cost of an induced immune response are associated with a heritable melanin-based colour trait in female tawny owls. J Anim Ecol. 2009;78:608-16.

George EL, Panos A. Does a high WBC count signal infection? Nursing. 2005;35:20-1.

Germaine SS, Rosenstock SS, Schweinsburg RE, Richardson WS. Relationships among breeding birds, habitat, and residential development in greater Tucson, Arizona. Ecol Appl. 1998;8:680-91.

Gilot-Fromont E, Jégo M, Bonenfant C, Gibert P, Rannou B, Klein F, et al. Immune phenotype and body condition in roe deer: individuals with high body condition have different, not stronger immunity. PLOS ONE. 2012; 7:e45576.

Godfrey PS, Toone BK, Carney MW, Flynn TG, Bottiglieri T, Laundy M, et al. Enhancement of recovery from psychiatric illness by methylfolate. Lancet. 1990;336:392-5.

GraczykTK, Cranfield MR, Shiff CJ. Extraction of Haemoproteus columbae (Haemosporina: Haemoproteidae) antigen from rock dove pigeons (Columba livia) and its use in an antibody ELISA. J Parasitol. 1994;80:713-8.

Gregoire A, Faivre B, Heeb P, Cezilly F. A comparison of infestation patterns by Ixodes ticks in urban and rural populations of the Common Blackbird Turdus merula. Ibis. 2002;144:640-5.

Grimm NB, Grove JG, Pickett ST, Redman CL. Integrated approaches to longterm studies of urban ecological systems. Bioscience. 2000;50:571-84.

Haase E, Ito S, Sell A, Wakamatsu K. Melanin concentrations in feathers from wild and domestic pigeons. J Hered. 1992;83:64-7.

Hanson HE, Koussayer B, Kilvitis HJ, Schrey AW, Maddox JD, Martin LB. Epigenetic potential in native and introduced populations of house sparrows (Passer domesticus). Integr Comp Biol. 2020;60:1458-68.

Hart BL. Behavioural defence. In: Clayton DH, Moore J, editors. Host-parasite evolution: general principle and avian models. Oxford: Oxford University Press; 1997. p. 59-77.

Hawkey CM, Dennett TB. A colour atlas of comparative veterinary haematology. London: Wolfe Publishing; 1989.

Hill GE, McGraw KJ. Bird colouration: function and evolution. Cambridge: Harvard University Press; 2006

Ishtiaq F, Rao M, Huang X, Bensch S. Estimating prevalence of avian haemosporidians in natural populations: a comparative study on screening protocols. Parasite Vectors. 2017;10:127.

Jacquin L, Haussy C, Bertin C, Laroucau K, Gasparini J. Darker female pigeons transmit more specific antibodies to their eggs than do paler ones. Biol J Linn Soc. 2013a;108:647-57.

Jacquin L, Lenouvel P, Haussy C, Ducatez S, Gasparini J. Melanin-based coloration is related to parasite intensity and cellular immune response in an urban free living bird: the feral pigeon Columba livia. J Avian Biol. 2011:42:11-5.

Jacquin L, Récapet C, Bouche P, Leboucher G, Gasparini J. Melanin-based coloration reflects alternative strategies to cope with food limitation in pigeons. Behav Ecol. 2012;23:907-15.

Jacquin L, Récapet C, Prévot-Julliard AC, Leboucher G, Lenouvel P, Erin N, et al. A potential role for parasites in the maintenance of color polymorphism in urban birds. Oecologia. 2013b;173:1089-99.

Jacquin L. Coloration mélanique et stratégies d'histoire de vie chez le pigeon biset urbain. Doctoral Thesis. University of Paris 6; 2011.

Jarry G, Baillon F. Hivernage de la tourterelle des bois (Streptopelia turtur) au Sénégal: étude d'une population dans la région de Nianing. Paris: Report of CRBPO; 1991.

Jiguet F, Sunnen L, Prévot AC, Princé K. Urban pigeons losing toes due to human activities. Biol Conserv. 2019;240:108241.

Johnston RF, Janiga M. Feral pigeons. Vol. 4. Oxford: Oxford University Press; 1995.

Karell P, Ahola K, Karstinen T, Kolunen H, Siitari H, Brommer JE. Blood parasites mediate morph-specific maintenance costs in a colour polymorphic wild bird. J Evol Biol. 2011;24:1783-92.

Kark S, Iwaniuk A, Schalimtzek A, Banker E. Living in the city: can anyone become an 'urban exploiter'? J Biogeogr. 2007;34:638-51.
Kilvitis HJ, Hanson H, Schrey AW, Martin LB. Epigenetic potential as a mechanism of phenotypic plasticity in vertebrate range expansions. Integr Comp Biol. 2017;57:385-95.

Kittilsen S, Schjolden J, Beitnes-Johansen I, Shaw JC, Pottinger TG, Sørensen C, et al. Melanin-based skin spots reflect stress responsiveness in salmonid fish. Horm Behav. 2009;56:292-8.

Kolomak IO, Berdnyk VP, Kyrychko OB, Nedosekov VV. Analysis of ultrastructural morphometric changes of pigeon kidneys affected by colibacteriosis. Transl Res Vet Sci. 2019;2:37-49.

Kramar DE, Carstensen B, Prisley S, Campbell J. Mercury concentrations in blood and feathers of nestling Bald Eagles in coastal and inland Virginia. Avian Res. 2019;10:3.

Krause ET, Krüger O, Hoffman II. The influence of inherited plumage colour morph on morphometric traits and breeding investment in zebra finches (Taeniopygia guttata). PLoS ONE. 2017;12:e0188582.

Krüger O, Lindström J. Lifetime reproductive success in common buzzard, Buteo buteo: from individual variation to population demography. Oikos. 2001:93:260-73.

Law GRJ. Blood samples from jugular vein of turkeys. Poult Sci. 1960;39:1450-2.

Le Viol I, Jiguet F, Brotons L, Herrando S, LindströmPearce-Higgins ÅJW, et al. More and more generalists: two decades of changes in the European avifauna. Biol Lett. 2012:8:780-2.

Leclaire S, Chatelain M, Pessato A, Buatois B, Frantz A, Gasparini J. Pigeon odor varies with experimental exposure to trace metal pollution. Ecotoxicology. 2019;28:76-85.

Luniak M. Synurbization - adaptation of animal wildlife to urban development. In: Shaw WW, Harris K, Vandruff L, editors. Proceedings of the 4th international symposium on urban wildlife conservation. Tucson, Arizona: University of Arizona; 2004. p. 50-5.

Madans JH, Webster KM. Health surveys. In: Wright JD, editor. International encyclopedia of the social and behavioral sciences. 2nd ed. Orlando: University of Central Florida; 2015. p. 725-30.

Martin LB. Stress and immunity in wild vertebrates: timing is everything. Gen Comp Endocrinol. 2009;163:70-6.

Martínez J, Vásquez RA, Venegas C, Merino S. Molecular characterisation of haemoparasites in forest birds from Robinson Crusoe Island: is the Austral Thrush a potential threat to endemic birds? Bird Conserv Int. 2015;25:139-52.

Martinossi-Allibert I, Clavel J, Ducatez S, Viol IL, Teplitsky C. Does habitat specialization shape the evolutionary potential of wild bird populations? J Avian Biol. 2017:48:1158-65.

Marzluff JM. Worldwide urbanization and its effects on birds. In: Marzluff JM, Bowman R, Donnelly R, editors. Avian ecology and conservation in an urbanizing world. Boston: Springer; 2001. p. 19-47.

McCarren S, Sumasgutner P, Tate G, Koeslag A, Amar A. Clinal variation in the polymorphic Black Sparrowhawk Accipiter melanoleucus is unrelated to infection by the blood parasite Haemoproteus nisi. J Ornithol. 2021;162:231-41.

Miller LK, Brooks R. The effects of genotype, age, and social environment on male ornamentation, mating behavior, and attractiveness. Evolution. 2005:59:2414-25.

Møller AP. Interspecific variation in fear responses predicts urbanization in birds. Behav Ecol. 2010;21:365-71.

Møller AP. Successful city dwellers: a comparative study of the ecological characteristics of urban birds in the Western Palearctic. Oecologia. 2009;159:849-58.

Moreno J, Møller AP. Are melanin ornaments signals of antioxydant and immune capacity in birds? Acta Zool Sin. 2006;52:202-8.

Nebel C, Harl J, Pajot A, Weissenböck H, Amar A, Sumasgutner P. High prevalence and genetic diversity of Haemoproteus columbae (Haemosporida: Haemoproteidae) in feral pigeons Columbae livia in Cape Town. South Africa Parasitol Res. 2020;119:447-63.

Obukhova NY. Geographic variation of color in the synanthropic Blue Rock Pigeon. Russ J Genet. 2001:37:649-58.

Ouali N, Belabed BE, Chenchouni H. Modelling environment contamination with heavy metals in flathead grey mullet Mugil cephalus and upper sediments from north African coasts of the Mediterranean Sea. Sci Total Environ. 2018;639:156-74.

Oxnard CE. One biologist's view of morphometrics. Annu Rev Ecol Evol Syst. 1978;9:219-41. 
Pal M, Pop P, Mahapatra A, Bhagat R, Hore U. Diversity and structure of bird assemblages along urban-rural gradient in Kolkata, India. Urban Forest Urban Green. 2019;38:84-96.

Parmesan C, Yohe G. A globally coherent fingerprint of climate change impacts across natural systems. Nature. 2003;421:37-42.

Pellegrino I, Cucco M, Calà E, Boano G, Pavia M. Plumage coloration and morphometrics of the Little Owl Athene noctua in the Western Palearctic. J Ornithol. 2020;161:1071-81.

Pérez JE, Nirchio M, Alfonsi C, Muñoz C. The biology of invasions: the genetic adaptation paradox. Biol Invas. 2006;8:1115-21.

Périquet JC. Le Pigeon: races, élevage et utilisation, reproduction, hygiène et santé. Collection Les cahiers de l'élevage, Ed. Rustica, Paris; 1998.

Pickett ST, Cadenasso ML, Grove JM, Boone CG, Groffman PM, Irwin E, et al. Urban ecological systems: scientific foundations and a decade of progress. J Environ Manage. 2011;92:331-62.

Pinheiro J, Bates D, DebRoy S, Sarkar D and R Core Team. nlme: linear and nonlinear mixed effects models. R package version 3.1-131. 2017. https:// cran.r-project.org/package $=$ nlme.

Pollack L, Ondrasek NR, Calisi R. Urban health and ecology: the promise of an avian biomonitoring tool. Curr Zool. 2017;63:205-12.

Quesada J, Senar JC. The role of melanin- and carotenoid-based plumage coloration in nest defence in the Great Tit. Ethology. 2007;113:640-7.

R Core Team. R: a language and environment for statistical computing. R foundation for statistical computing. 2020. https://www.R-project.org/.

Rasmussen PC, Anderton JC. Birds of south Asia: the Ripley guide: attributes and status. 1st Edn, Vol. 2. Washington and Barcelona: Smithsonian Institution and Lynx Edicions; 2005.

Récapet C, Dauphin L, Jacquin L, Gasparini J, Prévot-Julliard AC. Eumelaninbased colouration reflects local survival of juvenile feral pigeons in an urban pigeon house. J Avian Biol. 2013;44:583-90.

Reyer HU, Fischer W, Steck P, Nabulon T, Kessler P. Sex-specific nest defense in house sparrows (Passer domesticus) varies with badge size of males. Behav Ecol Sociobiol. 1998;42:93-9.

Roulin A, Almasi B, MeichtryStier KS, Jenni L. Eumelanin- and pheomelaninbased colour advertise resistance to oxidative stress in opposite ways. J Evol Biol. 2011;24:2241-7.

Roulin A, Altwegg R, Jensen H, Steinsland I, Schaub M. Sex-dependent selection on an autosomal melanic female ornament promotes the evolution of sex ratio bias. Ecol Lett. 2010;13:616-26.

Roulin A, Altwegg R. Breeding rate is associated with pheomelanism in male and with eumelanism in female barn owls. Behav Ecol. 2007;18:563-70.

Roulin A, Gasparini J, Bize P, Ritschard M, Richner H. Melanin-based colorations signal strategies to cope with poor and rich environments. Behav Ecol Sociobiol. 2008;62:507-19.

Roulin A, Jungi TW, Pfister H, Dijkstra C. Female barn owls (Tyto alba) advertise good genes. Proc R Soc Lond B Biol. 2000;267:937-41.

Roulin A, Riols C, Dijkstra C, Ducrest AL. Female plumage spottiness signals parasite resistance in the barn owl (Tyto alba). Behav Ecol. 2001;12:103-10.

Roulin A. The evolution, maintenance and adaptive function of genetic colour polymorphism in birds. Biol Rev. 2004;79:815-48.
Rumsfeld JS. Health status and clinical practice: when will they meet? Circulation. 2002;106:5-7.

Saino N, Romano M, Rubolini D, Ambrosini R, Caprioli M, Milzani A, et al. Viability is associated with melanin-based coloration in the barn swallow (Hirundo rustica). PLoS ONE. 2013;8:e60426.

Samuel MD, Woodworth BL, Atkinson CT, Hart PJ, LaPointe DA. Avian malaria in Hawaiian forest birds: infection and population impacts across species and elevations. Ecosphere. 2015;6:104.

Schultz PW, Gouveia WV, Cameron LD, Tankha G, Schmuck P, Franěk M. Values and their relationship to environmental concern and conservation behavior. J Cross-Cult Psychol. 2005;36:457-75.

Shochat E, Warren PS, Faeth SH, Mclntyre NE, Hope D. From patterns to emerging processes in mechanistic urban ecology. Trend Ecol Evol. 2006;21:186-91.

Sol D, Jovani R, Torres J. Geographical variation in blood parasites in feral pigeons: the role of vectors. Ecography. 2000;23:307-14.

Stevens RWC, Ridgway GJ. A technique for bleeding chickens from the jugular vein. Poultry Sci. 1966:45:204-5.

Stone KD, Prussin C, Metcalfe DD. IgE, mast cells, basophils, and eosinophils. J Allergy Clin Immunol. 2010;125:S73-80.

Stöppler MC, Shiel WC, Credo Reference (Firm), WebMD (Firm). Webster's new world medical dictionary, 3rd ed.; Redo Reference: Boston, MA, USA; Wiley: Hoboken, NJ, USA. 2014; 480 p.

Sumasgutner P, Rose S, Koeslag A, Amar A. Exploring the influence of urbanization on morph distribution and morph-specific breeding performance in a polymorphic African raptor. J Raptor Res. 2018;52:19-30.

The GIMP team. GIMP 2.8.10. 2014. www.gimp.org.

Tostes R, Vashist U, Scopel KKG, Massard CL, Daemon E, D'Agosto M. Plasmodium spp. and Haemoproteus spp. infection in birds of the Brazilian Atlantic Forest detected by microscopy and polymerase chain reaction. Pesq Vet Bras. 2015:35:67-74.

Uhm TG, Kim BS, Chung IY. Eosinophil development, regulation of eosinophilspecific genes, and role of eosinophils in the pathogenesis of asthma. Allergy Asthma Immunol Res. 2012:4:68-79.

Valkiūnas G, Palinauskas V, Ilgūnas M, Bukauskaitè D, Dimitrov D, Bernotienè $R$, et al. Molecular characterization of five widespread avian haemosporidian parasites (Haemosporida), with perspectives on the PCR-based detection of haemosporidians in wildlife. Parasitol Res. 2014;113:2251-63.

Van den Brink V, Dreiss AN, Roulin A. Melanin-based coloration predicts natal dispersal in the barn owl Tyto Alba. Anim Behav. 2012;84:805-12.

Vignieri SN, Larson JG, Hoekstra HE. The selective advantage of crypsis in mice. Evolution. 2010;64:2153-8.

Vlahov D, Freudenberg N, Proietti F, Ompad D, Quinn A, Nandi V, et al. Urban as a determinant of health. J Urban Health. 2007;84:16-26.

Wei T, Simko V. R package "corrplot": Visualization of a Correlation Matrix (Version 0.84). 2017. https://github.com/taiyun/corrplot.

Yeh PJ. Rapid evolution of a sexually selected trait following population establishment in a novel habitat. Evolution. 2004:58:166-74.

\footnotetext{
Ready to submit your research? Choose BMC and benefit from:

- fast, convenient online submission

- thorough peer review by experienced researchers in your field

- rapid publication on acceptance

- support for research data, including large and complex data types

- gold Open Access which fosters wider collaboration and increased citations

- maximum visibility for your research: over 100M website views per year
}

At $\mathrm{BMC}$, research is always in progress.

Learn more biomedcentral.com/submissions 